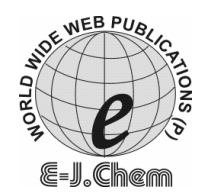

http://www.e-journals.net
ISSN: 0973-4945; CODEN ECJHAO

E-Journal of Chemistry 2010, 7(3), 1055-1065

\title{
Inhibitory Action of Borassus Flabellifer Linn. (Palmyra Palm) Shell Extract on Corrosion of Mild Steel in Acidic Media
}

\author{
P. R. VIJAYALAKSHMI*, R. RAJALAKSHMI and S. SUBHASHINI \\ *Department of Chemistry, Dr. G.R. Damodaran College of Science, \\ Coimbatore - 641 014, Tamil Nadu, India. \\ Department of Chemistry, Avinashilingam University For Women, \\ Coimbatore - 641 043, Tamil Nadu, India. \\ kamramvijib128@gmail.com
}

Received 11 November 2009; Accepted 5 January 2010

\begin{abstract}
The inhibitory effect of extract obtained from destructive distillation of palmyra palm (Borassus flabellifer Linn.) shell on the corrosion of mild steel in $0.5 \mathrm{M}$ $\mathrm{H}_{2} \mathrm{SO}_{4}$ and $1 \mathrm{M} \mathrm{HCl}$ was investigated using weight loss and electrochemical measurement techniques. The results show that the inhibition efficiency increases with increase of palmyra palm shell extract concentration. The maximum inhibition efficiency in $0.5 \mathrm{M} \mathrm{H}_{2} \mathrm{SO}_{4}$ and $1 \mathrm{M} \mathrm{HCl}$ was found to be $97.65 \%$ and $98.11 \%$ for a period of $24 \mathrm{~h}$ with $3 \% \mathrm{v} / \mathrm{v}$ concentration of the inhibitor respectively. Thermodynamic parameters were evaluated from temperature studies. Results were fitted into suitable adsorption isotherms. Electrochemical measurements infer that the extract acted through mixed mode of inhibition. Efforts were made to analyze the effectiveness of shell extract of palmyra palm in industrial processes.
\end{abstract}

Keywords: Palmyra palm shell, Mild steel, Corrosion inhibition, GC-MS.

\section{Introduction}

Mild steel is the material of choice in many industries due to its low cost and easy availability. Acids are used in many industries especially for cleaning, pickling and descaling. In order to reduce the corrosive action in aggressive environment, the inhibitory nature of many organic compounds containing heteroatoms like $\mathrm{N}, \mathrm{S}$ and $\mathrm{O}$ which have high basicity and electron density has been studied ${ }^{1}$. Many heterocyclic compounds such as triazoles $^{2}$, quinoline ${ }^{3}$ and pyridine ${ }^{4}$ were evaluated for their corrosion inhibition.

Natural products like lignin and tannin ${ }^{5}$, cinchona alkaloids ${ }^{6}$ and pomegranate alkaloids ${ }^{7}$ have been evaluated as very effective acid corrosion inhibitors in standard as well as in stringent conditions. Inhibition of corrosion was studied with the extracts of Antrographis paniculata $^{8}$, Thespesia populnea ${ }^{9}$, Mangifera indica ${ }^{10}$, Datura metal ${ }^{11}$, Mentha pulgeium ${ }^{12}$, Sesbania grandiflora seeds ${ }^{13}$, Ficus benghalensis bark ${ }^{14}$, Psidium gerajanra (bark) and Callistemos (leaves) ${ }^{15}$, Canavalia ensiformis ${ }^{16}$ etc. The natural inhibitors studied have been 
found to be highly eco-friendly and possess no threat to the environment. Hence the present investigation was aimed to evaluate the efficacy of palmyra palm (Borassus flabellifer Linn.) shell extract against the corrosion of mild steel.

\section{Experimental}

Mild steel specimen with the following chemical composition in wt $\% \mathrm{C}, 0.11 ; \mathrm{Si}, 0.061$; Mn, 0.197; S, 0.023; P, 0.025; Ni, 0.010; Mo, 0.013; Cr, 0.037 and Fe, 99.524; was used. Mild steel was cut into small coupons of $1 \times 5 \mathrm{~cm}^{2}$ size and used for immersion studies. Lacquered samples with $1 \mathrm{~cm}^{2}$ exposed area were used for electrochemical studies. The specimens were duly prepared by mechanical polishing and degreasing methods. They were dried, stored in desiccators and used for all studies. Since $\mathrm{H}_{2} \mathrm{SO}_{4}$ and $\mathrm{HCl}$ are widely used in industries, stock solution of $0.5 \mathrm{M} \mathrm{H}_{2} \mathrm{SO}_{4}$ and $1 \mathrm{M} \mathrm{HCl}$ were prepared and used throughout the experiment. The Borassus flabellifer Linn. fruit was collected from the tree and shell was removed, cleaned, chopped into small pieces, air dried and stored at room temperature prior to use. $230 \mathrm{~g}$ of air dried shell pieces was transferred to a $2000 \mathrm{~mL}$ round bottomed flask, directly heated in a mantle with water condenser at about $80{ }^{\circ} \mathrm{C}$ in the absence of air and without a carrier solvent (destructive distillation). The products obtained are;(i) A gaseous mixture or wood gas. (ii) $85 \mathrm{~mL}$ of aqueous distillate obtained which was used as inhibitor. (iii) $10 \mathrm{~mL}$ of a thick black liquid or wood tar which was separated from the aqueous distillate using a separating funnel. (iv) $80 \mathrm{~g}$ of a solid residue or wood charcoal was left in the round bottomed flask.

In order to identify the individual compounds in the aqueous distillate of Borassus flabellifer Linn. shell extract Gas Chromatograph - Mass Spectrometry (GC-MS) technique was used ${ }^{17}$. The identification of the isolated volatile compounds was achieved by comparing obtained mass spectra of unknown peaks with those stored in the NIST (National Institute of Standards and Technology) and Wiley mass spectral electronic libraries. Identifications were confirmed by comparison with authentic substances used as references and by use of linear retention indices (LRI). Relative area values (as a percentage of total volatile composition) were directly obtained from total ion current (TIC). All analyses were carried out in duplicate. The chromatogram of aqueous distillate is shown in Figure 1.

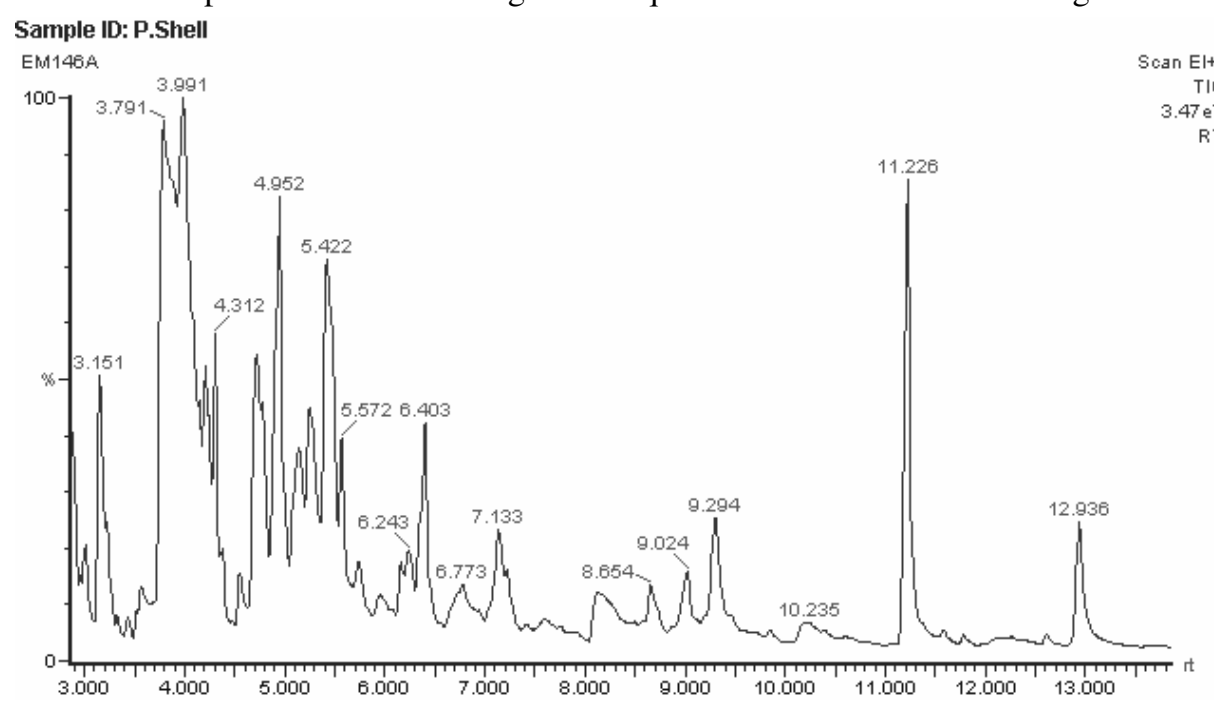

Figure 1. Total Ion Chromatogram resulting from the aqueous distillate of palmyra palm shell extract obtained by destructive distillation. 
The chemical compounds identified in the Borassus flabellifer Linn. shell extract are presented in Table 1.

Table 1. The chemical compounds identified in the aqueous distillate of Borassus flabellifer Linn. shell extract by GC-MS analysis

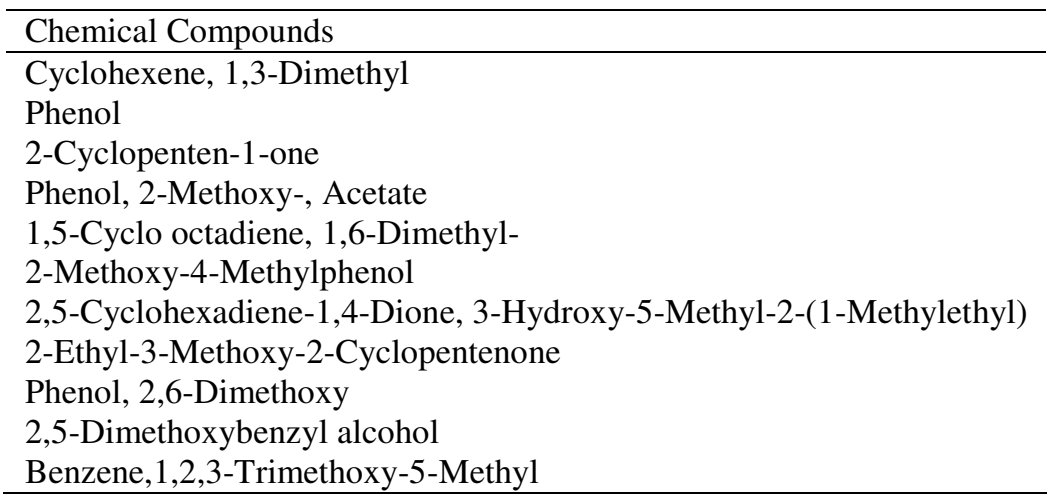

Weight loss measurements were carried out in triplicate for different duration viz, $(1 / 2,1,3,6$ and $24 \mathrm{~h})$ and temperature variation was from $303 \mathrm{~K}$ to $343 \mathrm{~K}$. From the weight loss values, corrosion rate and inhibition efficiency were determined. Electrochemical studies were carried out using conventional three-electrode system, Solartron ElectroAnalyzer (model 1280B) interfaced with an IBM computer, zplot and corrware software was used for data acquisition and analysis. Efforts have been taken to analyze the effectiveness of the shell extract of Borassus flabellifer Linn. in industrial processes.

\section{Results and Discussion}

\section{Effect of corrodent concentration and immersion time}

The variation of inhibition efficiency for different concentration of shell extract of Borassus flabellifer Linn. is listed in the Table 2. Maximum inhibition efficiency for $0.5 \mathrm{M} \mathrm{H}_{2} \mathrm{SO}_{4}$ and $1 \mathrm{M} \mathrm{HCl}$ was found to be $97.65 \%$ and $98.11 \%$ at $24 \mathrm{~h}$ with $3 \% \mathrm{v} / \mathrm{v}$ concentration of the inhibitor respectively. This behavior may be attributed to the increase of the surface coverage by the extract, which retards the corrosion of mild steel.

Table 2. Inhibition efficiency as a function of immersion time and concentration.

\begin{tabular}{ccccccc}
\hline \multirow{2}{*}{$\begin{array}{c}\text { Acid } \\
\text { Medium }\end{array}$} & $\begin{array}{c}\text { Inhibitor } \\
\text { Conc., \%v/v }\end{array}$ & \multicolumn{5}{c}{ Inhibition Efficiency, \% } \\
\cline { 3 - 7 } $0.5 \mathrm{M} \mathrm{H}_{2} \mathrm{SO}_{4}$ & 0.5 & 72.81 & 78.90 & 85.33 & 87.80 & 80.25 \\
& 1.0 & 73.94 & 86.59 & 87.88 & 92.73 & 92.69 \\
& 1.5 & 76.08 & 88.99 & 89.19 & 95.33 & 94.25 \\
& 2.0 & 78.84 & 89.93 & 92.03 & 95.25 & 96.08 \\
& 2.5 & 79.83 & 91.29 & 92.62 & 95.78 & 96.73 \\
& 3.0 & 84.93 & 93.51 & 93.05 & 96.34 & 97.65 \\
$1 \mathrm{M} \mathrm{HCl}$ & 0.5 & 78.37 & 76.78 & 74.93 & 80.25 & 95.92 \\
& 1.0 & 86.79 & 80.89 & 76.14 & 83.20 & 96.71 \\
& 1.5 & 87.78 & 83.44 & 82.63 & 84.53 & 97.02 \\
& 2.0 & 88.98 & 88.31 & 82.30 & 86.74 & 97.63 \\
& 2.5 & 91.06 & 90.40 & 84.01 & 87.22 & 97.74 \\
& 3.0 & 93.21 & 91.34 & 84.25 & 87.19 & 98.11 \\
\hline
\end{tabular}


From Table 2, it is noticed that in $0.5 \mathrm{M} \mathrm{H}_{2} \mathrm{SO}_{4}$ the inhibition efficiency increases with increase of immersion time and concentration of shell extract from $2.0 \% \mathrm{v} / \mathrm{v}$. From the values it can be inferred that as the immersion time increases the protection efficiency increases up to $97.65 \%$ at $24 \mathrm{~h}$, thereby indicating the enhanced stability of the adsorbed constituents of the extract on mild steel surface. In $1 \mathrm{M} \mathrm{HCl}$ the inhibition efficiency increased with increase in concentration and immersion time of the extract to give a protection efficiency of $98.11 \%$. The consistent behavior of palmyra palm shell extract with an increase in immersion time indicates the stability and persistence of the inhibitor layer on the metal surface ${ }^{18}$.

\section{Influence of temperature}

Temperature can modify the interaction between iron electrode and acid in the presence / absence of inhibitor. To determine the energy of activation of corrosion and thermodynamic parameters, the weight loss measurements were carried out from $303 \mathrm{~K}-343 \mathrm{~K}$ in the absence and presence of various concentration of palmyra palm shell extract.

From Figure 2, it was inferred that in $0.5 \mathrm{M} \mathrm{H}_{2} \mathrm{SO}_{4}$ inhibition efficiency increases with increase in concentration of the shell extract at all investigated temperature in both medium. The inhibition efficiency also increases with increase in temperature of the test solution upto $333 \mathrm{~K}$. A slight decrease in inhibition efficiency was observed at $343 \mathrm{~K}$. However at $343 \mathrm{~K}$, the value of inhibition efficiency was found to $93.82 \%$ at $3 \% \mathrm{v} / \mathrm{v}$ concentration. Hot acid solutions are generally used for removing mill scales (oxide scales) from the metal surface in various industries at elevated temperature such as $60{ }^{\circ} \mathrm{C}$ in $\mathrm{HCl}$ and upto $95{ }^{\circ} \mathrm{C}$ in $\mathrm{H}_{2} \mathrm{SO}_{4}{ }^{19}$. In the present investigation, the extract functions as a promising inhibitor at higher concentration and at higher temperature. In $1 \mathrm{M} \mathrm{HCl}$, the inhibition efficiency increases with increase in temperature at higher concentration of the palmyra palm shell extract. Even at lower concentration of the shell extract could also furnish remarkable inhibition efficiency. This can be explained by Putilova ${ }^{20}$, the decrease in the inhibition efficiency of the inhibitor with increase in temperature might be due to adsorption and desorption of inhibitor. Adsorption and desorption of inhibitor molecules continuously occurs at the metal surface and an equilibrium exists between these two processes at a particular temperature. With the increase of temperature the equilibrium between adsorption and desorption processes is shifted leading to a higher desorption rate than adsorption until equilibrium is again established at a different value of equilibrium constant ${ }^{21}$.

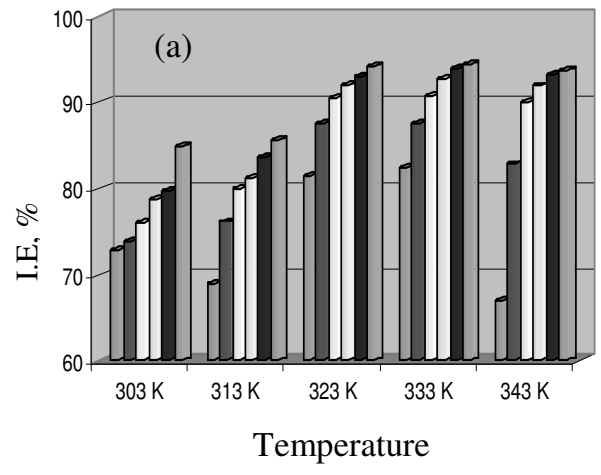

$\square 0.5 \square 1 \square 1.5 \square 2 \square 2.5 \square 3$

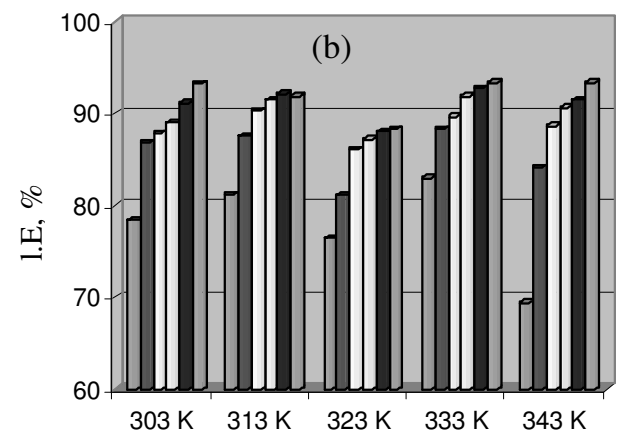

Temperature

$\square 0.5 \square 1 \square 1.5 \square 2 \square 2.5 \square 3$

Figure 2. Effect of temperature on the corrosion of mild steel in (a) $0.5 \mathrm{M} \mathrm{H}_{2} \mathrm{SO}_{4}$ and (b) $1 \mathrm{M} \mathrm{HCl}$ in the presence of various inhibitor concentrations. 


\section{Adsorption Isotherm}

The phenomenon of interaction between the metal surface and inhibitor can be better understood in terms of adsorption isotherm. A plot of $\log (\theta /(1-\theta)) v s . \log C$ and $\theta v s . \log C$ gave a straight line indicating that the inhibitor under the study obeys Langmuir and Temkin adsorption isotherms respectively ${ }^{22}$. This may also infer that there is a molecular interaction among the adsorption particles and metal surface.

\section{Kinetic and thermodynamic parameters}

The Arrhenius plots of $\log$ C.R vs. 1/T for both uninhibited and inhibited systems are rectilinear. The activation energies $(\mathrm{Ea})$ calculated from the slopes of the curves given in Table 3 . The marked changes in Ea suggest that the inhibitor may either participate in the electrode process or may change the potential difference of the metal solution interface by adsorption.

Table 3. Kinetic and thermodynamic parameters of mild steel in presence of palmyra palm shell extract in $0.5 \mathrm{M} \mathrm{H}_{2} \mathrm{SO}_{4}$ and $1 \mathrm{M} \mathrm{HCl}$.

\begin{tabular}{|c|c|c|c|c|c|c|c|c|c|}
\hline \multirow{2}{*}{$\begin{array}{c}\text { Acid } \\
\text { Medium }\end{array}$} & \multirow{2}{*}{$\begin{array}{c}\text { Inhibitor } \\
\text { Conc., \% v/v }\end{array}$} & \multirow{2}{*}{$\begin{array}{c}\mathrm{Ea} \\
\mathrm{kJ} / \mathrm{mol}\end{array}$} & \multicolumn{5}{|c|}{$-\Delta \mathrm{G}, \mathrm{kJ} / \mathrm{mol}$} & \multirow{2}{*}{$\begin{array}{c}\Delta \mathrm{S} \\
\mathrm{kJ} / \mathrm{mol}\end{array}$} & \multirow{2}{*}{$\begin{array}{c}\Delta \mathrm{H} \\
\mathrm{kJ} / \mathrm{mol}\end{array}$} \\
\hline & & & $303 \mathrm{~K}$ & $313 \mathrm{~K}$ & $323 \mathrm{~K}$ & $333 \mathrm{~K}$ & $343 \mathrm{~K}$ & & \\
\hline $0.5 \mathrm{M}$ & Blank & 60.96 & - & - & - & - & - & - & - \\
\hline \multirow{6}{*}{$\mathrm{H}_{2} \mathrm{SO}_{4}$} & 0.5 & 59.93 & 14.32 & 14.30 & 16.59 & 16.44 & 15.41 & 0.031 & +5.30 \\
\hline & 1.0 & 45.53 & 12.72 & 13.45 & 16.00 & 16.53 & 17.03 & 0.113 & -21.21 \\
\hline & 1.5 & 36.87 & 11.98 & 12.98 & 15.76 & 16.32 & 16.54 & 0.112 & -21.43 \\
\hline & 2.0 & 33.61 & 11.66 & 12.42 & 15.50 & 16.25 & 16.39 & 0.126 & -26.36 \\
\hline & 2.5 & 30.00 & 11.25 & 12.29 & 15.25 & 16.18 & 16.34 & 0.130 & -27.90 \\
\hline & 3.0 & 32.29 & 11.68 & 12.23 & 15.29 & 15.92 & 16.05 & 0.120 & -24.76 \\
\hline $1 \mathrm{M}$ & Blank & 51.71 & - & - & - & - & - & - & - \\
\hline \multirow[t]{6}{*}{$\mathrm{HCl}$} & 0.5 & 53.11 & 15.08 & 16.03 & 15.78 & 17.40 & 15.73 & 0.007 & +13.79 \\
\hline & 1.0 & 47.68 & 14.83 & 15.49 & 14.67 & 16.69 & 16.18 & 0.040 & +2.34 \\
\hline & 1.5 & 46.43 & 14.04 & 15.16 & 14.56 & 15.94 & 16.11 & 0.042 & +1.61 \\
\hline & 2.0 & 44.96 & 13.61 & 14.78 & 14.05 & 15.88 & 15.89 & 0.051 & -1.80 \\
\hline & 2.5 & 45.04 & 13.63 & 14.32 & 13.64 & 15.61 & 15.56 & 0.056 & -3.86 \\
\hline & 3.0 & 45.18 & 13.92 & 13.95 & 13.23 & 15.35 & 15.82 & 0.077 & -10.85 \\
\hline
\end{tabular}

The values of free energy of adsorption were calculated using the standard equation ${ }^{23}$,

$$
\log \mathrm{C}=\log (\theta /(1-\theta))-\log \mathrm{B}
$$

Where, $\log \mathrm{B}=-1.74-(-\Delta \mathrm{G} / 2.303 \mathrm{RT}), \theta=$ Surface coverage, $\mathrm{C}=$ Concentration,

$\Delta \mathrm{G}=$ Free energy of adsorption, $\mathrm{R}=$ Gas Constant, $\mathrm{T}=$ Temperature.

The values obtained are presented in Table 3. Results obtained indicate that the values of $\Delta \mathrm{G}$ are negative in both the cases indicating the spontaneous adsorption of palmyra palm shell extract and it is strongly adsorbed on the mild steel surface ${ }^{24}$. The increase in $\Delta \mathrm{G}$ with increasing concentration also indicates the strength of adsorption. The value of $\Delta \mathrm{G}$, indicates that the inhibitor function by physically adsorbing on the surface of the mild steel. Generally values of $\Delta \mathrm{G}$ up to $-20 \mathrm{~kJ} \mathrm{~mol}^{-1}$ are consistent with electrostatic interaction between charged molecules and charged metal (which indicates physisorption) while those more negative than $40 \mathrm{~kJ} \mathrm{~mol}^{-1}$ involves charge sharing or transfer from the inhibitor molecules to the metal surface to form a co-ordinate type of bond (which indicates chemisorptions) ${ }^{25}$.Physical adsorption is as a result of electrostatic attraction between charged metal surface and charged species in bulk of the solution. Adsorption of negatively charged species can also protect the positively charged metal surface acting with a negatively charged intermediate such as acid anions adsorbed on the metal surface ${ }^{26}$. 
The heat of adsorption $\Delta \mathrm{H}$ and entropy of adsorption $\Delta \mathrm{S}$ are calculated from free energy of adsorption by Gibbs Helmholtz equation. The values of $\Delta H$ indicate that both physical and chemical adsorption take place (i.e. comprehensive adsorption) in both the system ${ }^{27}$. That is to say, since the adsorption heat approached the general chemical reaction heat, the chemical adsorption might occur accompanied by physical adsorption (electrostatic interaction). The positive $\Delta \mathrm{S}$ values accompanied with endothermic adsorption process in both acid medium ${ }^{28}$.

\section{Electrochemical measurements}

\section{Polarization studies}

To find out the nature of the inhibitor, mode of action, mechanism of reaction, electrochemical techniques such as Tafel, linear and impedance measurements were carried out. Typical potentiodynamic polarizing curve showing the inhibitory action of palmyra palm shell extract for both the acids is given in Figure 3. The corrosion parameters such as $\mathrm{E}_{\text {corr }}, \mathrm{I}_{\text {corr }}$, Tafel slope constants $\left(b_{a}\right.$ and $\left.b_{c}\right)$, linear polarization resistance $\left(R_{p}\right)$ obtained from these curves is presented in Table $4 . \mathrm{I}_{\text {corr }}$ was found to decrease as the concentration of the inhibitor increases. This confirms the inhibitory action of palmyra palm shell extract on metal surface. The $\mathrm{E}_{\text {corr }}$ value has not been shifted to any particular direction from the blank value, which also indicates that the inhibitor acts through mixed mode of inhibition. Tafel slopes $b_{a}$ and $b_{c}$ obtained in the presence and absence of the palmyra palm shell extract in both medium revealed that the inhibition of corrosion of mild steel is under mixed control in both anodic dissolution and cathodic hydrogen evolution mechanism are affected in presence of the inhibitor.

It can be concluded from the results obtained that palmyra palm shell extract act as a mixed type inhibitor in both acidic media. The increase in $R_{p}$ values with increase in concentration of inhibitor indicates the effective inhibitory nature of the inhibitor. The inhibition efficiency calculated by polarization technique was found to increase with increase in concentration of the extract. Inhibition efficiency was found to be $88.29 \%$ and $82.59 \%$ in $0.5 \mathrm{M} \mathrm{H}_{2} \mathrm{SO}_{4}$ and $1 \mathrm{M} \mathrm{HCl}$ with $3 \% \mathrm{v} / \mathrm{v}$ of the extract.

Table 4. Electrochemical and corrosion parameters for mild steel in the presence of palmyra palm shell extract in $0.5 \mathrm{M} \mathrm{H}_{2} \mathrm{SO}_{4}$ and $1 \mathrm{M} \mathrm{HCl}$.

\begin{tabular}{ccccccc}
\hline $\begin{array}{c}\text { Acid } \\
\text { Medium }\end{array}$ & $\begin{array}{c}\text { Inhibitor } \\
\text { Conc., \%v/v }\end{array}$ & $\begin{array}{c}\mathrm{I}_{\text {corr }} \\
\mathrm{mA} \mathrm{cm}-2\end{array}$ & $\begin{array}{c}-\mathrm{E}_{\text {corr }} \\
\mathrm{V} / \mathrm{dec}\end{array}$ & $\begin{array}{c}\mathrm{b}_{\mathrm{a}} \\
\mathrm{mV} / \mathrm{dec}\end{array}$ & $\begin{array}{c}\mathrm{b}_{\mathrm{c}} \\
\mathrm{mV} / \mathrm{dec}\end{array}$ & $\mathrm{IE}, \%$ \\
\hline $0.5 \mathrm{M} \mathrm{H}_{2} \mathrm{SO}_{4}$ & Blank & 6346 & 505 & 192.16 & 151.84 & - \\
& 0.5 & 2878 & 502 & 168.66 & 108.38 & 54.64 \\
& 1.0 & 2642 & 505 & 164.66 & 105.94 & 58.36 \\
& 1.5 & 2055 & 498 & 151.12 & 98.28 & 67.61 \\
& 2.0 & 1624 & 493 & 146.98 & 91.99 & 74.40 \\
& 2.5 & 914 & 486 & 143.93 & 78.85 & 85.59 \\
$1 \mathrm{M} \mathrm{HCl}$ & 3.0 & 743 & 484 & 141.16 & 84.02 & 88.29 \\
& $\mathrm{Blank}$ & 6964 & 497 & 196.27 & 152.97 & - \\
& 0.5 & 2713 & 497 & 169.93 & 126.81 & 61.04 \\
& 1.0 & 2389 & 501 & 164.10 & 126.65 & 65.69 \\
& 1.5 & 1927 & 502 & 163.34 & 121.93 & 72.32 \\
& 2.0 & 1696 & 503 & 154.65 & 119.24 & 75.64 \\
& 2.5 & 1449 & 503 & 148.40 & 104.05 & 79.19 \\
& 3.0 & 1212 & 502 & 119.54 & 103.25 & 82.59 \\
\hline
\end{tabular}



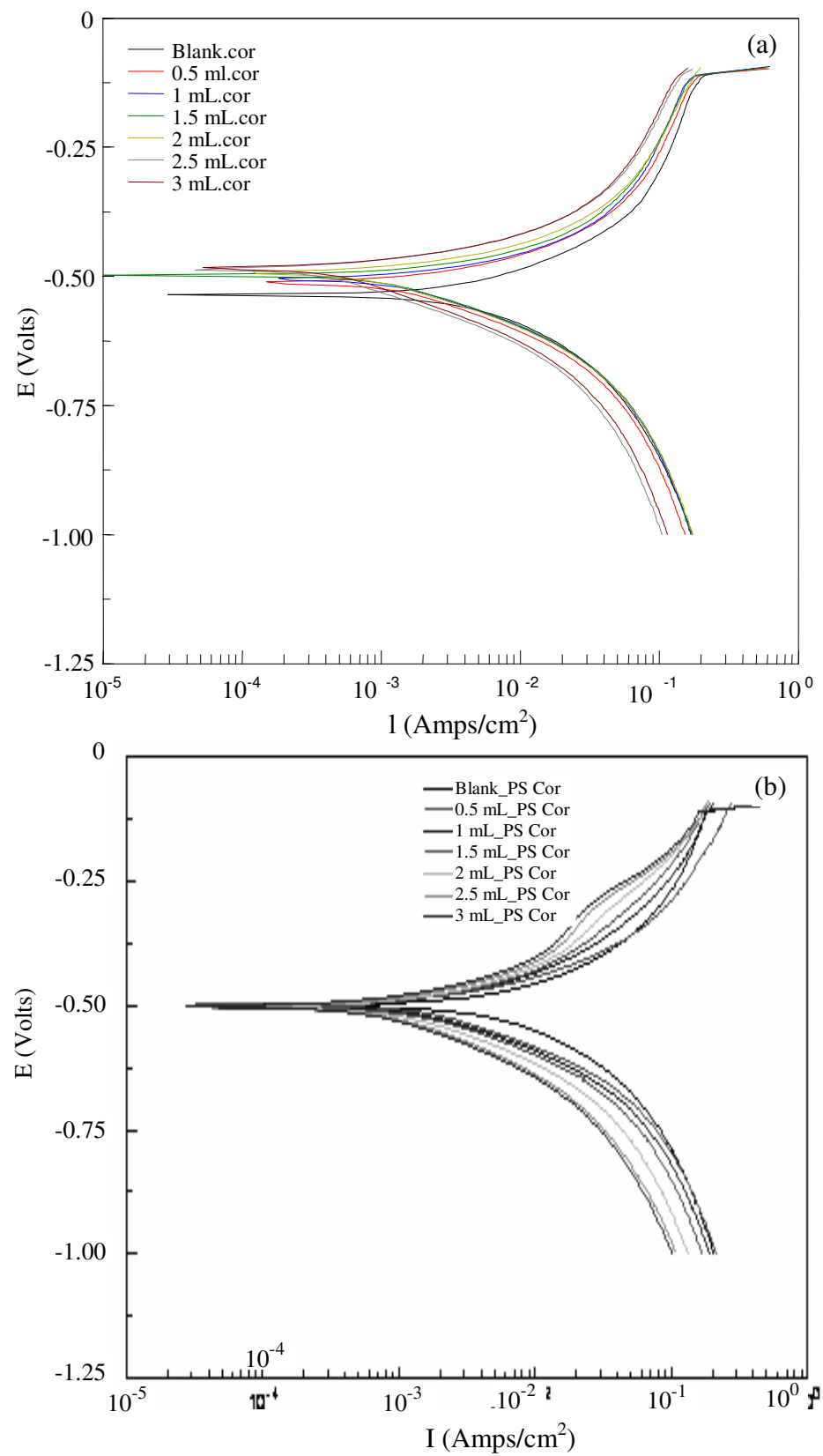

Figure 3. Polarization curve of mild steel in presence of palmyra palm shell extract in (a) $0.5 \mathrm{M} \mathrm{H}_{2} \mathrm{SO}_{4}$ and (b) $1 \mathrm{M} \mathrm{HCl}$.

\section{Impedance studies}

Impedance parameters such as $\mathrm{R}_{\mathrm{ct}}$ and $\mathrm{C}_{\mathrm{dl}}$ obtained are presented in the Table 5. Values of $\mathrm{R}_{\mathrm{ct}}$ and $\mathrm{C}_{\mathrm{dl}}$ infer that the inhibition is due to adsorption of inhibitor on mild steel surface. The radius of the semicircle was found to increase with increase in the concentration of the inhibitor (Figure 4). Impedance diagrams show that the corrosion of mild steel is controlled 
inhibitor (Figure 4) by charge transfer process. Maximum inhibition efficiency using $\mathrm{R}_{\mathrm{ct}}$ values was found to be $95.5 \%$ and $86.53 \%$ in $0.5 \mathrm{M} \mathrm{H}_{2} \mathrm{SO}_{4}$ and $1 \mathrm{M} \mathrm{HCl}$ respectively at $3 \% \mathrm{v} / \mathrm{v}$ concentration. Using $\mathrm{C}_{\mathrm{dl}}$ values the maximum surface coverage was found to be 0.612 and 0.605 in $0.5 \mathrm{M} \mathrm{H}_{2} \mathrm{SO}_{4}$ and $1 \mathrm{M} \mathrm{HCl}$ at $3 \% \mathrm{v} / \mathrm{v}$ concentration. The results show that palmyra palm shell extract is quit effective in retarding dissolution of mild steel in both examined media.
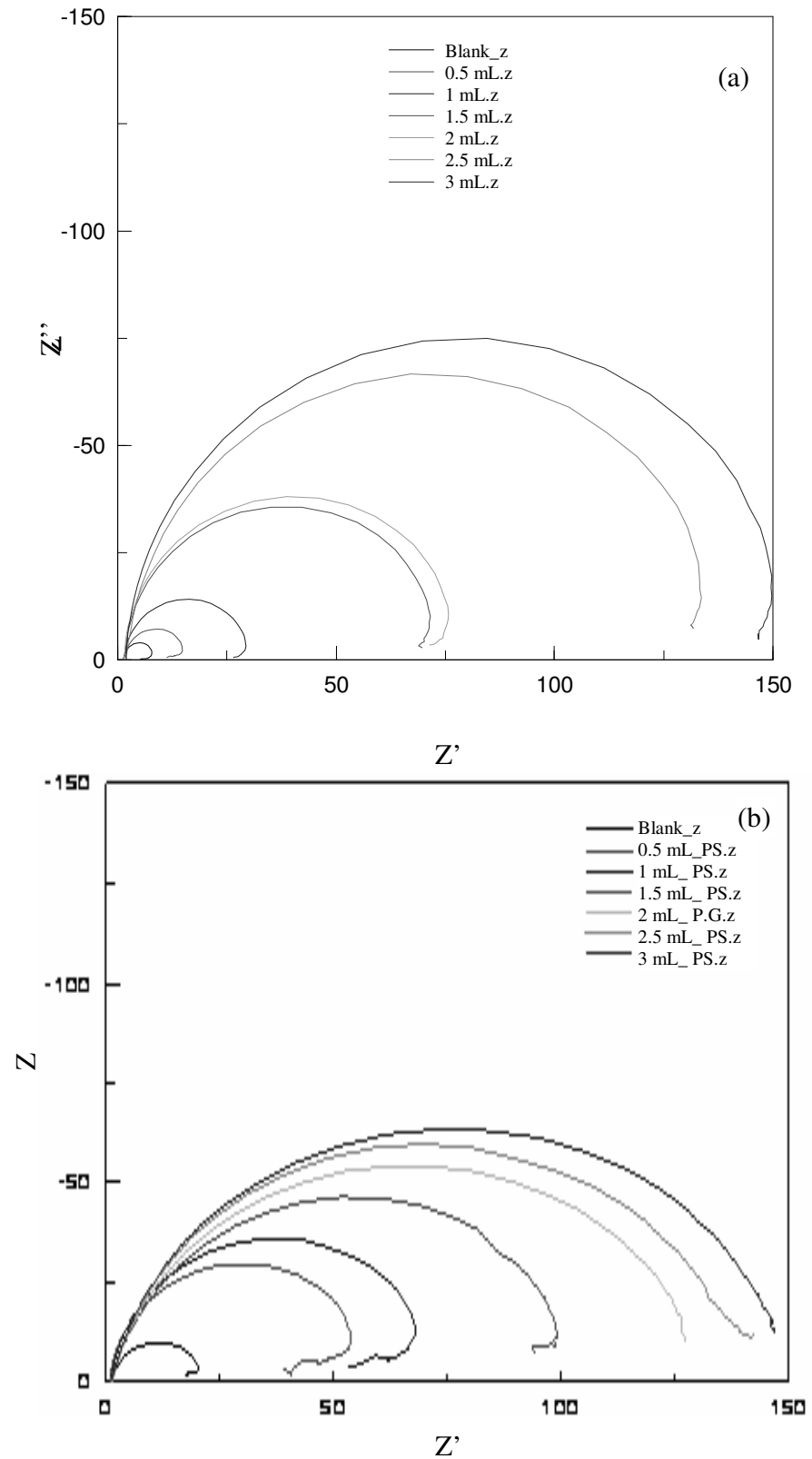

Figure 4. Nyquist plot of mild steel in presence of palmyra palm shell extract in (a) $0.5 \mathrm{M}$ $\mathrm{H}_{2} \mathrm{SO}_{4}$ and (b) $1 \mathrm{M} \mathrm{HCl}$. 
Table 5. Electrochemical and Impedance Parameters of mild steel in the presence of palmyra palm shell extract in $0.5 \mathrm{M} \mathrm{H}_{2} \mathrm{SO}_{4}$ and $1 \mathrm{M} \mathrm{HCl}$.

\begin{tabular}{lccccccc}
\hline $\begin{array}{c}\text { Acid } \\
\text { Medium }\end{array}$ & $\begin{array}{c}\text { Inhibitor } \\
\text { Conc., \%v/v }\end{array}$ & $\begin{array}{c}\mathrm{R}_{\mathrm{ct}} \\
\left.(\mathrm{ohm} \mathrm{cm})^{2}\right)\end{array}$ & $\mathrm{IE}, \%$ & $\begin{array}{c}\mathrm{C}_{\mathrm{dl}} \times 10^{-4} \\
\mathrm{Fcm}^{2}\end{array}$ & $\theta$ & $\begin{array}{c}\mathrm{R}_{\mathrm{p}} \\
\left(\mathrm{ohm} \mathrm{cm}^{2}\right)\end{array}$ & $\mathrm{IE}, \%$ \\
\hline $0.5 \mathrm{M}$ & Blank & 6.61 & - & 2.456 & - & 5.972 & - \\
$\mathrm{H}_{2} \mathrm{SO}_{4}$ & 0.5 & 14.11 & 53.15 & 2.194 & 0.106 & 8.820 & 32.29 \\
& 1.0 & 28.64 & 76.92 & 2.106 & 0.142 & 9.236 & 35.33 \\
& 1.5 & 68.43 & 90.34 & 1.598 & 0.349 & 9.682 & 38.31 \\
& 2.0 & 72.31 & 90.85 & 1.577 & 0.357 & 12.783 & 53.28 \\
& 2.5 & 131.06 & 94.95 & 1.392 & 0.433 & 19.745 & 69.75 \\
$1 \mathrm{M} \mathrm{HCl}$ & 3.0 & 147.23 & 95.51 & 0.952 & 0.612 & 21.781 & 72.58 \\
& Blank & 20.06 & - & 2.223 & - & 3.884 & - \\
& 0.5 & 55.29 & 63.71 & 1.579 & 0.289 & 5.107 & 23.94 \\
& 1.0 & 70.30 & 71.46 & 1.485 & 0.331 & 5.321 & 27.00 \\
& 1.5 & 101.61 & 80.25 & 1.299 & 0.415 & 6.533 & 40.54 \\
& 2.0 & 130.60 & 84.64 & 1.057 & 0.524 & 8.344 & 53.45 \\
& 2.5 & 138.24 & 85.48 & 0.928 & 0.582 & 20.946 & 81.45 \\
& 3.0 & 149.01 & 86.53 & 0.877 & 0.605 & 24.427 & 84.09 \\
\hline
\end{tabular}

Industrial application of palmyra palm shell extract on mild steel acid medium

There is a class of chemical inhibitors which work by removing electrons from the metal, thereby pushing the potential into a positive region where an oxide film spontaneously forms. This results in a stable, passive surface with a very low corrosion rate. Industries apply this technology in processes where the inhibitor can be conveniently added without causing environmental or health problems.

One of the categories of corrosion inhibitors are those which form a surface layer of a foreign chemical compound provided by the inhibitor itself. Many commercial inhibitor for example, calgon is a solution of sodium hexametaphosphate, a condensed phosphate polymer based on the unit $\left(-\mathrm{PO}_{3}\right)_{\mathrm{n}}$ is used as an inhibitor in potable water systems (drinking water) because it is non-toxic and is widely used in large institutions such as hotels and hospitals ${ }^{29}$.

In the present investigation, efforts are taken to test the palmyra palm shell extract as corrosion inhibitors in various industries at coimbatore. The reports furnished from the industries reveal that the palmyra palm shell extract function effectively as a corrosion inhibitor. Industries can utilize this type of low cost / zero cost inhibitor for this pickling processes.

Performance evaluations of Palmyra palm shell extract using weight loss and electrochemical measurements

Both techniques are best suited for the corrosion inhibition of palmyra palm shell extract on mild steel surface. However the value of inhibition efficiency calculated from electrochemical measurement are lower than those obtained from weight loss data (Figure 5). The difference in inhibition efficiency by different techniques can be attributed to the fact that weight loss method gives average corrosion rates which electrochemical gives instantaneous corrosion rate. The difference may be expected to arise because of the difference in time required to form an adsorbed layer, which brings down corrosion. 


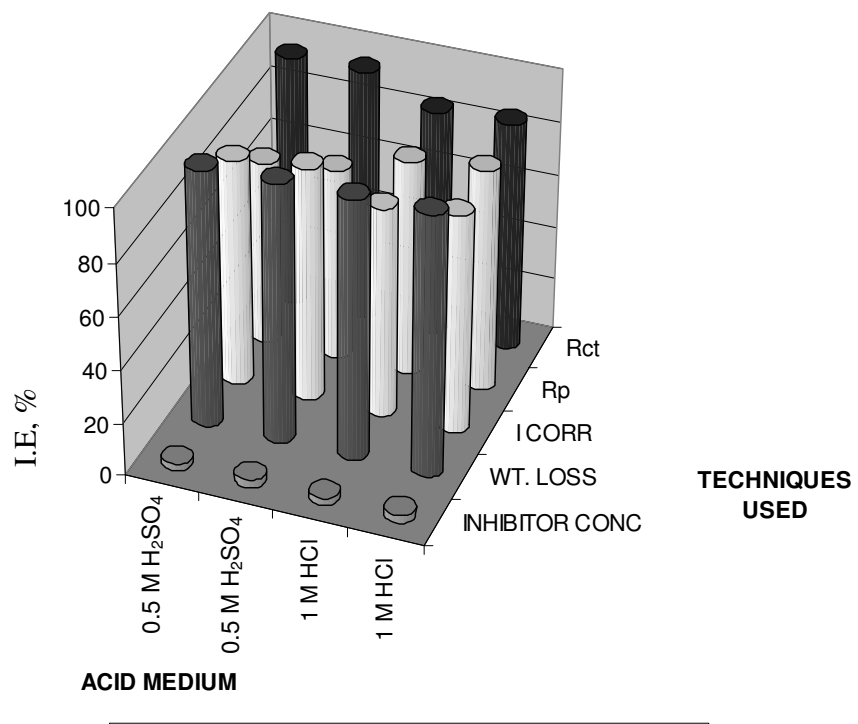

$\square$ INHIBIOR CONC $\square$ WT. LOSS $\square$ ICORR $\square$ Rp $\square$ Rct

Figure 5. Comparison between conventional method and electrochemical techniques of palmyra palm shell extract in $0.5 \mathrm{M} \mathrm{H}_{2} \mathrm{SO}_{4}$ and $1 \mathrm{M} \mathrm{HCl}$.

\section{Mechanism of inhibition process}

The mechanism of inhibition of corrosion is generally believed to be due to the metal surface. The polar units (i.e.) heteroatom like N, O, S etc., present in the inhibitor are acting as reaction centre for adsorption process.

Referring the chemical compounds identified in the Borassus flabellifer Linn. shell extract presented in Table 1, it can be seen that most of the compounds identified are oxygen containing compounds. The hetero oxygen atom in the structure makes possible its adsorption by co-ordinate type linkage through the transfer of lone pairs of electron of oxygen atoms to the vacant $d$-orbitals of metal surface atoms, giving a stable chelate five or six membered ring with ferrous ions ${ }^{30}$. The simultaneous adsorption of oxygen atoms forces the palmyra palm shell extract molecule to be horizontally oriented at the metal surface, which led to increase the surface coverage and consequently protect efficiency even in the case of low inhibitor concentration. The adsorption between the metal and organic constituents of the extract might be through electrostatic interaction.

\section{Conclusions}

The palmyra palm shell extract was proved to be a potential inhibitor for mild steel in $0.5 \mathrm{M}$ $\mathrm{H}_{2} \mathrm{SO}_{4}$ and $1 \mathrm{M} \mathrm{HCl}$. The inhibition efficiency increases with inhibitor concentration, time and temperature. Experimental results are well fitted into Langmuir and Temkin adsorption isotherm. Kinetic and thermodynamic parameters infer the strong adsorption of inhibitor molecule on mild steel surface and also the inhibition is by spontaneous comprehensive adsorption (physical and chemical adsorption) of inhibitor on mild steel surface. Electrochemical measurements confirm the mixed mode of inhibition. Thus the palmyra palm (Borassus flabellifer Linn.) shell extract was proved to be an effective eco friendly and low cost inhibitor. 


\section{References}

1. Pandian Bothi Raja and Mathur Gopalakrishnan Sethuraman, Mater Lett., 2008, 62(1), 113-116.

2. Satyanandam B, Balakrishnan K and Subramanyan N, Brit Corros J., 1970, 5(11), 270.

3. Mehta G N and Sastry T P, II ${ }^{\text {nd }}$ International Symp Industrial and Oriental Basic Electrochemistry, (SAEST) IIT, Madras, Tech sec VI, 1980.

4. Zakvi S J and Mehta G N, J Electrochem Soc., India, 1987, 36(3), 143-145.

5. El-Hosary A A, Saleh R M and Shans El Din A M, Corros Sci., 1972, 61(7), 689.

6. Mehta G N and Sastry T P, J Electrochem Soc., India, 1981, 30, 281.

7. Jha L J, Hussain A and Singh G, J Electrochem Soc., India,1991, 40(4) 153-157.

8. Ramesh S P, Vinodkumar K P, Sethuraman M G, Bull Electrochem., 2001, 17(3), 141-144.

9. Maheswari D, Rajalakshmi R, Subhashini S, Viswanathan M and Sivakamasundari S, Proceedings of Enviro., Coimbatore, India, 2001, 534.

10. Loto C A, Mohammed A I and Loto R O, Corrosion Prevention and Control, 2003, 50(3), 107 - 118.

11. El-Etre A Y, Applied Surface Science, 2006, 252 (24), 8512 - 8525.

12. Bouyanzer A, Hammouti B and Majidi L, Mater Lett., 2006, 60(23), 2840 - 2843

13. Subhashini S, Sathyanarayana S, Marikkannu C and Sivakamasundari S, 2002, ISAEST VII, 146.

14. Rajalakshmi R, Sathyanarayana S, Marikkannu C and Sivakamasundari S, 2002, ISAEST VII, 142.

15. Manohari G and Rajalakshmi R, Ninth Seminar Proceedings, Tamil Nadu State Council for Science and Technology, India, 2001, 318.

16. Prithiba A, Sathiyanarayana S, Rajalakshmi R and Sivakamasundari S, Proceedings of $11^{\text {th }}$ NCCI, Baroda, India, 2003, 3.

17. Tadeusz Wolski, Krzysztof Tambor, Helena Rybak-Chmielewska and Bogdan Kedzia, J Apicultural Sci., 2006, 50(2), 115-126.

18. Mohammed Ajmal, Danish Janal and Quraishi. M A, Anti-Corrosion Methods and Materials, 2000, 47, 100-106.

19. Abd El-Maksoud S A, Int J Electrochem Sci., 2008, 3, 528 - 555.

20. Putilova I N, Balezin S A and Barannik V P, Metallic corrosion inhibition, Pergamon Press, New York, 1960, 31.

21. Rawat N S and Singh A K, Bull Electrochem., 1987, 3, 7.

22. Bockris J O' M and Swinkels D A J, J Electrochem Soc., 1964, 111, 736.

23. Bag S K, Chakraborty S B and Chaudhuri S R, J Indian Chem Soc., 1996, 73, 113-118.

24. Ebenso E E, Mater Chem Phys., 2003, 79, 58 - 70.

25. El-Etre A Y, J Colloid Interface Sci., 2007, 314(2), 578 - 583.

26. Umoren S A and Ebenso E E, Mater Chem Phys., 2007, 106(2-3), 387.

27. Mu G, Li X and Liu G, Corros Sci., 2005, 47, 1932 - 1952.

28. Thomas $\mathbf{J}$ M and Thomas W J, Introduction to the Principles of Heterogeneous Catalysis, $5^{\text {th }}$ Ed, Academic Press, London, 1981, 14 - 18.

29. Gerard Beranger, Corrosion and Protection of Metals and Alloys, John Wiley \& Sons, Inc., 2008.

30. Abdallah A, Portugaliae Electrochimica Acta, 2004, 22(2), 161-175. 


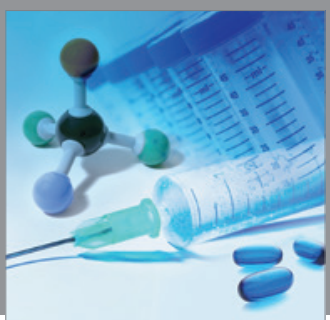

International Journal of

Medicinal Chemistry

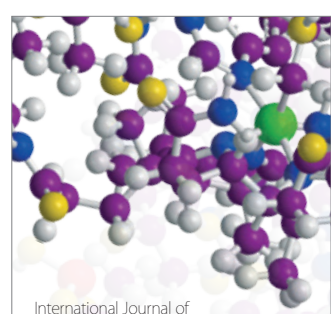

Carbohydrate Chemistry

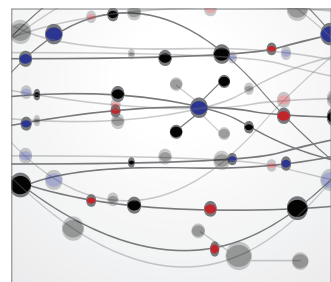

The Scientific World Journal
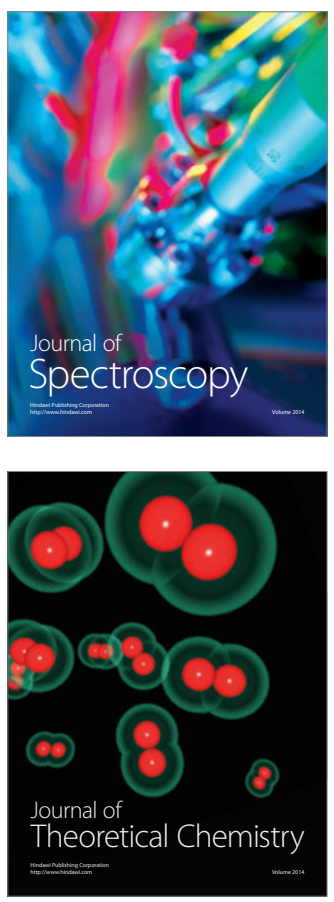
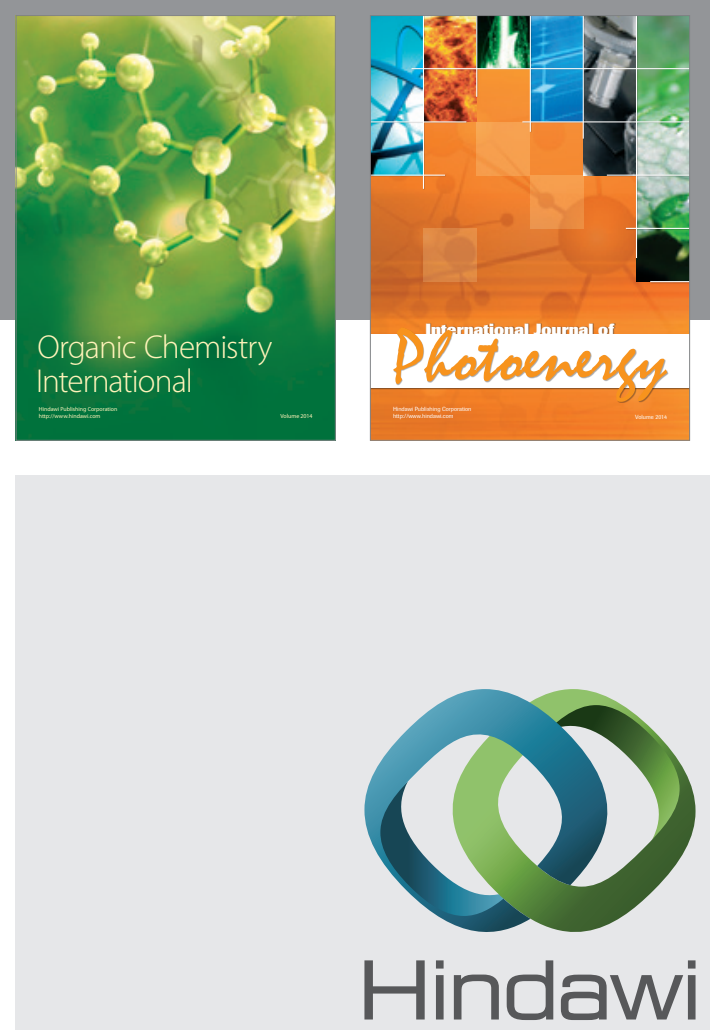

Submit your manuscripts at

http://www.hindawi.com
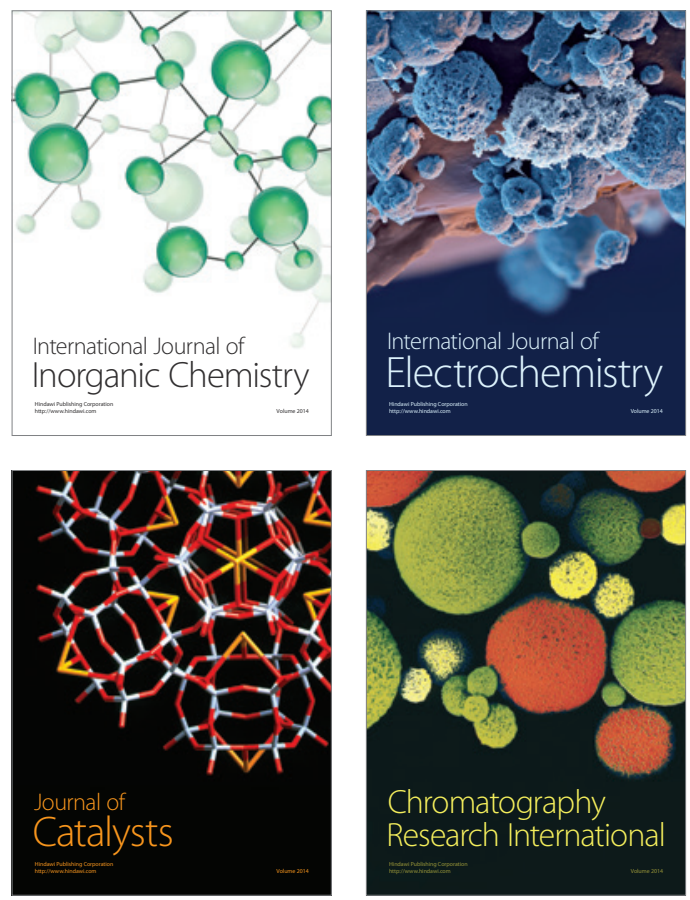
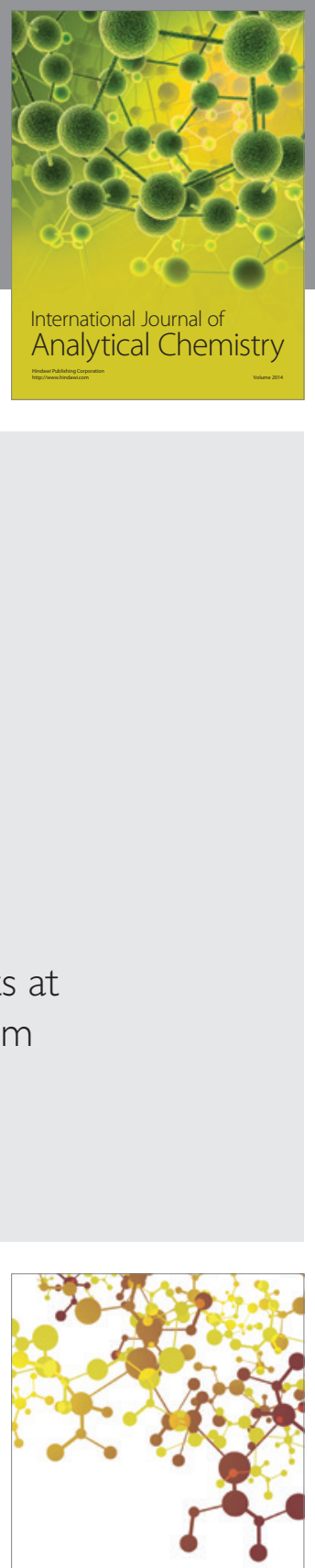

Journal of

Applied Chemistry
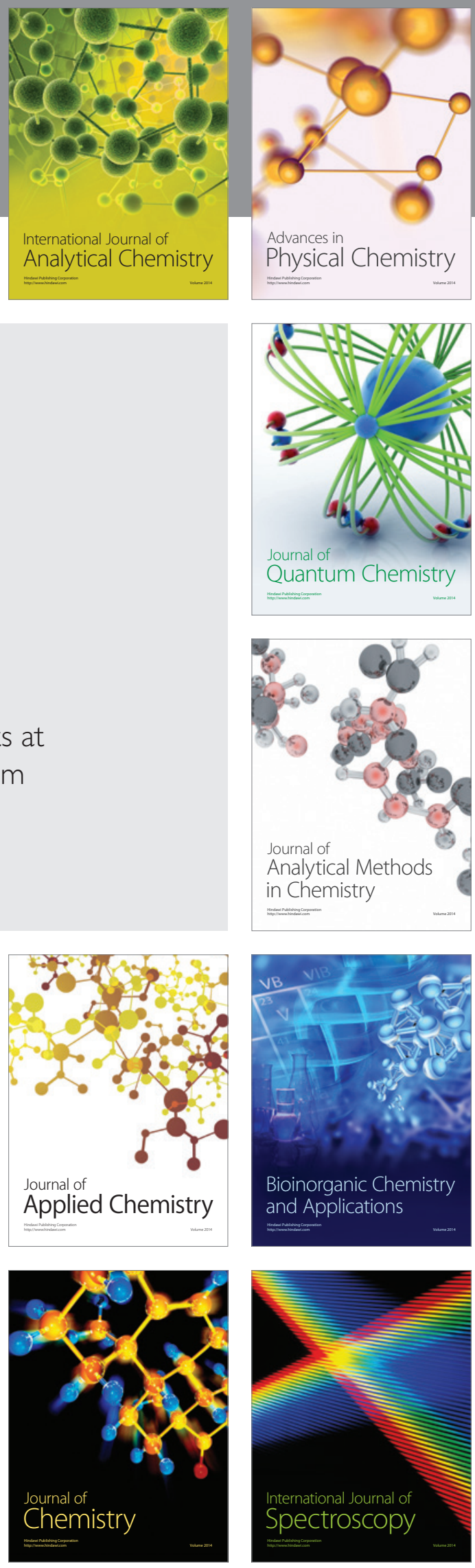